\title{
Social Computing Implications for Technology Usage and Team Interactions in Virtual Teams
}

\author{
Archisman Majumdar \\ Quantitative Methods and Information Systems \\ Indian Institute of Management Bangalore \\ India \\ Email: archisman.majumdar08@iimb.ernet.in
}

\author{
S. Krishna \\ Quantitative Methods and Information Systems \\ Indian Institute of Management Bangalore \\ India \\ Email: skrishna@iimb.ernet.in
}

\begin{abstract}
-
For a new generation of mostly younger users, using social technologies has become a habit. At the same time, there has been increasing adoption of social computing technologies as collaborative tools to facilitate knowledge sharing and team interactions in work contexts. Previous research has looked into the effects of differences in prior technology use and habit strength on intentions to use and actual usage of technology. Researchers have also shown how knowledge of the capabilities of a technology, affects team interactions and usage of the technology in virtual teams. Hence to understand the impact of collaborative technology usage on team interactions, it is important to consider both the employees' knowledge of the capabilities of the technology as well as his/her prior experiences or habits with the technology. Considering these observations, and the ubiquity of global virtual teams, this paper proposes to conduct an empirical field study to find out the effects of employees prior usage of social media on their social media usage and team interactions within a virtual team setting.

Index Terms-virtual teams, social computing, collaborative technology, digital natives, technology adoption
\end{abstract}

\section{INTRODUCTION}

\section{A. Background}

Social Computing Technologies (wikis, social networks, blogs, microblogs, etc.) are being increasingly adopted within organizations. Such tools are also being increasingly used within teams to facilitate knowledge sharing and team interactions. While many organizations have successfully adopted such technologies, many others are still undecided. Previous research has looked into the difference of the effects of prior technology use on the intention to use a technology [1], [2], [3]. At the same time, another stream of researchers have looked into how knowledge of the capabilities of the technology used affects team interactions [4], [5]. This study proposes to combine the two streams of research, in the context of social media use in particular. The objective of the study is to find out how differences in previous experiences with social media between the team members affect team interactions, technology usage and team performance. We are particularly interested in finding out how an employee's knowledge of social media gained through his/her usage of such tools outside organizations, can be used to help make collaborative tools and team interactions better within organizations.

\section{B. Context and Motivation}

Most of the large organizations today employ virtual teams to some degree [6]. Collaborative technology has been shown to significantly aid the functioning of such teams [7]. However, members of the team might differ in their views of and ability to use such technology. Two factors which significantly affect the impact of such diversity on team interactions are the advent of a new generation of workers, and the emergence of a new set of technologies, broadly termed Web 2.0 technologies. Technologies are now more open and collaborative in nature, shifting "the locus of control in creation and configuration of content to the end users" [8], while social networking applications have, "technologically enabled conversational communication in a mass scale" [9]. Web 2.0, social software, social computing, etc. are some of the words used to describe this trend [8]. The deployment of this new generation of tools for collaboration presents a new set of opportunities to the organization. However, most managers are still finding it difficult to get the employees to contribute to enterprise social platforms, blogs and wikis. The advent of a new generation of users who are more habituated to using such technologies can help managers overcome some of these challenges. Many of these users have been using computers from a very young age. Prensky [10] argues that young people's growing up surrounded by technology not just leads to differing usage, but also to people thinking differently about technology. The expectations and technology habits of the 'digital natives' from collaborative tools are hence likely to be different. Researchers have indicated that prior experience and habit play an important role in the decision to continue using technology within the organization [1], [11], [3]. Thus there is a need to understand the implications for team interactions in a virtual team setting due to the emergence of this new group of users and the new generation of technologies. These three factors the rise of the virtual teams, the introduction of web 2.0 tools for collaboration and the emergence of a new generation of technologically experienced workers, together constitute the context of the study. Keeping these observations in mind, this research seeks to explore the broad research question - What are the implications for Global Virtual Teams due to the advent of a new group of users proficient with social media and web 


\section{0 technologies?}

\section{Purpose of Research}

The purpose of the research is to:

1) Identify what are the relevant constructs in ascertaining the effects of prior social media usage habits on social media usage and team interactions within a virtual team setting.

2) Develop a theoretical model incorporating the identified constructs to explain how these constructs are interrelated.

3) To empirically test the model.

\section{REVIEW OF RELEVANT RESEARCH}

\section{A. Global Virtual Teams}

A virtual team consists of "a) two or more people who b) collaborate interactively to achieve common goals, while c) at least one of the team members work at a different location, organization or at a different time so that d) communication and coordination is predominantly based on electronic communication media" [6]. Global virtual teams are internationally distributed groups of people representing different organizations and functions. These people are with an organizational mandate to make or implement decisions with international components and implications [12]. With their ability to transcend barriers of time, space, nationality and organization [13] Global Virtual Teams (GVT) has been called one of the most fascinating direct results of globalization and the continuing proliferation of ICT [14]. More than $60 \%$ of professional employees work in virtual teams and more than half of all companies with over 5000 employees use virtual teams [15]. A significant amount of research has been done on virtual teams in organizations. For a more in-depth understanding of the literature on virtual teams, a number of literature reviews and meta analysis on teams, virtual teams and collaborative technology are available (e.g. [6], [16], [15], [17]).

\section{B. Collaborative Technology in Virtual Teams}

Collaborative technologies (CT) refer to a variety of electronic tools including email, group support systems (GSS), intranets, groupware, and computer-conferencing, to name a few, used by members of groups to communicate with each other, coordinate activities and execute tasks [4]. One of the most important considerations in the functioning of virtual teams has been the collaborative capabilities of available technology [18]. Technical infrastructure provides the backbone for virtual teams to work effectively [19] and plays an important role for their effectiveness and success. Hence understanding both the capabilities of the collaborative technology and how teams embrace and use such collaborative systems, is critical for organizational success [7]. For collaborative technology to be effective, it needs to be used by the majority of the members in the team. Various models of Technology adoption, as well as post adoption usage, have been studied in the Information Systems literature. The various theoretical frameworks which have been used to understand technology usage within groups have mostly been influenced by media richness [20], media synchronity [21], technology adoption [22], and the task technology fit [23] perspectives.

1) Capabilities of the Technology: The capabilities of the media [20], its fit with the task [23] and communication context [24], as well as the experience of the users with the technology [25], all play important roles in determining the usage of the technology by the users. Media Richness Theory [20] hierarchically classified communication media on the basis of the ability of a media to convey and communicate different cues and provide rapid feedback. A richer media (e.g. face to face) was claimed to convey more cues in comparison to a leaner media (e.g. email). According to the theory communication media should be matched to a task "based on the need to reduce uncertainty, or the absence of information to perform a task, and equivocality, or the absence of a shared understanding of what information means in connection with the task being carried out" [26]. Carte and Chidambaram [4] argued that a collaborative tool had both reductive (e.g. visual anonymity) as well as additive (e.g. electronic trail) capabilities. Both sets of capabilities, were claimed to aid in the working of virtual teams. Becker et al. [5] observed that in situations where "the burden of work is borne more by the user", it was the user's knowledge of those technologies which become an "important determinant in the use of the technology".

2) Role of Prior Experience: Deviating from the rational, deliberate, cognitive decision making models, when researching technology adoption and usage, Limayem and Hirt [1] argued that there is also a need to focus on the factors which are internal to the individual. They reintroduced the notion of habit and through empirical studies established how habit and prior IT experience are also important predictors of IT usage [1].

This role of experience was also indicated in a number of studies in groupware usage literature. Channel Expansion Theory posited that the perceived richness of a media is dependent on the experience with the media [27]. Chidambaram [25], in an experimental study showed that, with the continuing use of a technology by the people over time, constraints to using the technology reduced significantly. Both the theories, in essence, acknowledge the role of the user's knowledge of the system as an important determinant of the usage of the technology in the organization.

Thus, we identify a clear need to incorporate the technology capabilities perspective [4] with perspectives on the role of prior experiences and habit [1] when discussing about technology usage in virtual teams. We also argue in the paper that a new generation of technology is going to make the role of prior experience and habit, even more important than earlier. This new group of technology has been called by various names, including, web 2.0, social software, social computing technologies. In the following section, we look at the literature pertaining to this new group of technologies in organizations. 


\section{Social Computing Software}

Social software refers to web-based applications that support human collaboration and communication [28]. This is a relatively new area of research with the definition of web 2.0 evolving and has considerable implications for practice. Organizations are increasingly making use of Web-based technologies that provide rapid and agile collaboration, information sharing, emergence, and integration capabilities in the extended enterprise [9].

We believe it is essential to understand the capabilities of social computing tools for collaborative work if they are to be used in virtual teams. Hence we extend the capabilities identified by Carte and Chidambaram [4] as shown in Table I.

In the following subsections we present a brief discussion on the main differences in the adoption and use of this new group of technologies by the younger generation of users.

1) Social Software Adoption and Usage: The limitations of current models of acceptance in their ability to explain Web 2.0 adoption and use have already been acknowledged [8]. New models to analyze the adoption of such technologies are being researched (e.g. Hsu and Lin [29], investigated the acceptance of blog usage while Zhao and Rosson [30], investigated microblog usage). To understand social software usage in virtual teams, it is hence necessary to incorporate some aspects from this adoption literature. However, this alone will not be sufficient because of the nuances of the virtual teams and the groupware adoption systems. The role of habit and prior experience is also a key determinant in the usage of such tools.

A recent stream of literature posits that habit and prior experience with technology will be significantly different among a particular section of people. This group of people has been variously called the digital natives, the millennials, Generation $Y$ and sometimes the net generation. This is the group who have for the first time in human history grown up surrounded by technology [10]. It is believed by some researchers that traditional IS assumptions that were true for digital immigrants (such as "users always resist technology") may no longer apply to this new group of users [31].

2) Technology Habits in the New Generation of Users: Digital Natives [10], are "a subset of the millennial generation who have grown up immersed in a networked world with access to ubiquitous digital technologies and the ability to learn and use them in fluent and sophisticated ways" [32]. Tapscott [33] claims that about 80 million digital natives will be entering the workplace and will want to be part of an "engage and collaborate" model within organizations rather than a "command and control model". A number of assumptions have been made in the literature about the computing abilities of the Digital natives. These include their preference for multitasking and nonlinear access to information, heavy reliance on communication technologies and access to information [34], ability to seamlessly transition between the use of traditional and ubiquitous information systems for both personal and professional purposes, porous boundaries between professional

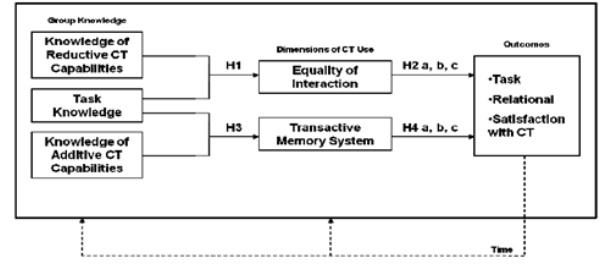

via

Fig. 1. Collaborative Technology Use in Virtual Teams [4]

and personal uses of the systems, a constant need to stay connected [31] and an almost intuitive difference in their usage of new technologies [35]. While digital natives use blogging to share personal experiences and treat personal blogging websites as forms of online journals, older users by contrast in general tend to use blogging sites more as intellectual tools to share and discuss ideas with their peers [10]. Considering the above observations, it is evident that the habits of social media usage will vary between the users on the basis of their prior use of technology, and possibly also on the basis of their 'digital nativity'.

\section{Gaps in Literature and Research Questions}

The academic literature contains many gaps in our knowledge about the interactions of the capabilities of collaborative technology and the working of a virtual team. While Becker, Carte and Chidambaram [36] have proposed a framework towards understanding how the knowledge of technology capabilities can impact the effectiveness of virtual teams, they however, do not mention the antecedents of this knowledge. This paper argues that prior experience as well as habit can play an important role in the formation of such perceptions about technology. While the role of habit strength and prior experience have been shown to influence technology usage, there is no framework that can explain this effect in a virtual team context. There is also a need to understand the capabilities of social computing technologies in support of group work and collaboration.

Based on our discussion of the literature and observing the gaps in literature we chose to pursue the following specific research questions

\section{Specific Research Questions}

1) What features in Collaborative Technologies used in Global Virtual Teams increase/decrease the Collaborative Technologies appropriation within Global Virtual Teams?

2) How does diversity in prior experience with Web 2.0 technologies affect Collaborative Technology usage in Global Virtual Teams?

3) What are the effects of member diversity in previous social media use on team interactions in Global Virtual Teams?

In the next section we will develop a theoretical framework based on our discussion of the literature. 
TABLE I

EXTENSION OF CT CAPABILITIES[4] TO SOCIAL COMPUTING TECHNOLOGIES

\begin{tabular}{|c|c|c|c|c|}
\hline Capabilities & SNS & Wiki & Blog & Microblog \\
\hline \multicolumn{5}{|l|}{$\begin{array}{l}\text { Reductive Capabili- } \\
\text { ties }\end{array}$} \\
\hline Visual Anonymity & Low & High & High & High \\
\hline $\begin{array}{l}\text { Equality of Partici- } \\
\text { pation }\end{array}$ & Low & High & High & High \\
\hline $\begin{array}{l}\text { Synchronous } \\
\text { Interaction }\end{array}$ & No & No & No & No \\
\hline \multicolumn{5}{|l|}{ Additive Capability } \\
\hline $\begin{array}{l}\text { Coordination } \\
\text { Support }\end{array}$ & No & No & No & \\
\hline Electronic trail & & & & Yes \\
\hline $\begin{array}{l}\text { Enhanced Capabili- } \\
\text { ties }\end{array}$ & $\begin{array}{l}\text { Social Network Vi- } \\
\text { sualization }\end{array}$ & Mass collaboration & $\begin{array}{lr}\text { Broadcast } & \text { personal } \\
\text { documents } & \text { and } \\
\text { artifacts } & \end{array}$ & $\begin{array}{l}\text { Broadcast short up- } \\
\text { dates }\end{array}$ \\
\hline
\end{tabular}

\section{THEORETICAL FRAMEWORK}

The model proposed by Becker, Carte and Chidambaram, [5] (Figure 1) provides an understanding of how the knowledge of collaborative technology capabilities affect team interactions. Developing on the concepts of technology capabilities [4] the authors go on to show that the knowledge of the capabilities is also a vital element in determining the usefulness of the technology in virtual teams. However, the model does not discuss about the possible antecedents to this difference in knowledge. As we observed in literature, there is evidence that this knowledge may be the result of prior use of the technology. In the context of social computing technologies and in particular for the new generation of workers, habit strength is likely to be one of the antecedents. This may vary across people of different generations.

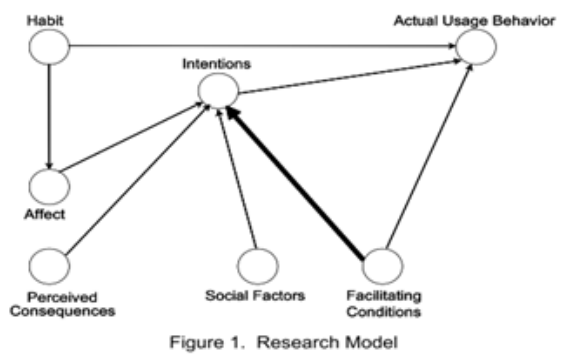

Fig. 2. Effect of Prior Use on IT continuance [1]

Hirt et al.'s [1] model of the role of habit strength on actual usage (Figure 2) is one of the possible explanations which can be extended to the study of social computing technology usage in virtual teams. Hence we believe it will be useful to combine the two models. Keeping the particular context of use in mind, we develop a framework suitable for exploring our research questions.

\section{A. Proposed Research Model}

Figure 3 shows the research model incorporating an individual's habit strength with respect to technology usage,

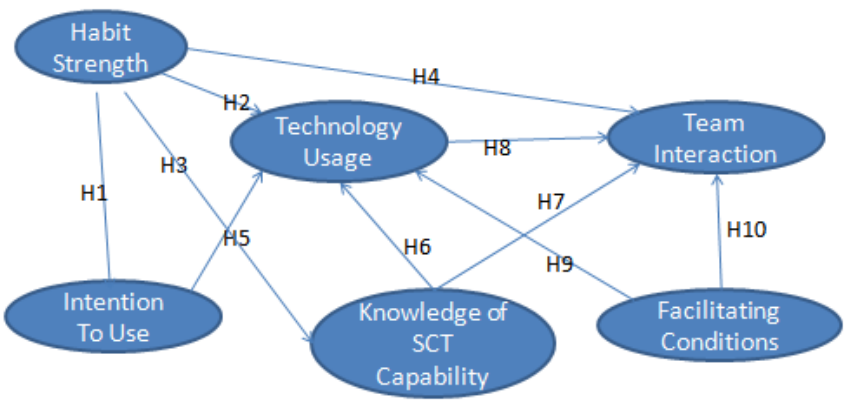

Fig. 3. Proposed Research Model

his/her knowledge of the technology capabilities, technology usage and team interactions. The model attempts to explain the antecedents to this difference in knowledge. In the model we have decided not to include task knowledge, since in the study we intend to control for it by looking at similar tasks. Also, task knowledge is not related to habit or usage and hence while we acknowledge the importance of this, we do not include it in this model for model parsimony. We do not look at the team outcome variables. We limit our discussion only to team interactions (relational interactions). This is because the link between team interaction and performance has been researched elsewhere. For a discussion about the studies of team interactions or processes, on team outcomes, one can refer to the virtual team review by Powell et al.[17]. The following paragraphs describe each of the constructs used in the model in more detail.

a) Team Interaction: Team interactions form one of the main components of the processes ${ }^{1}$ in a virtual team. They act as a mediator between the input (like diversity, technology, etc.) and the output (team performance, satisfaction, etc.). Carte and Chidambaram [4] term this mediating variable as

\footnotetext{
${ }^{1}$ Processes refer to "members interdependent acts that convert inputs to outputs through cognitive, verbal and behavioral activities directed towards organizing task work to achieve collective goals." [3].
} 
relational interaction. They include the sub constructs - relational conflict, task based conflict and cohesion. Task conflict consists of disagreements about group members perceptions of task issues such as goals, key decision areas and appropriate choice of action [37]. Task conflict positively affects team performance [38] while increasing group creativity and effectiveness [39]. Relationship conflict refers to disagreements and incompatibilities between group members about personal issues that are not task related, such as social events and gossip. This includes personality differences, animosity and annoyance between individuals [37]. In this study we concentrate on the role of technology usage and habit strength on such team interactions. We do not look at the relationship between team interaction and team effectiveness, since this has already been established in a number of prior studies [37].

b) Habit Strength and Intention to Use: Prior experience with Technology and habit has been shown to significantly affect IT continuance intention as well as IT use within organizations. Prior experience [40] as well as Habit [41] are significant predictors of computer use. Although the studies on the impact of these variables on technology usage were carried out for different types of Information Systems, the results are likely to be valid even for social computing or collaborative technology usage within organizations. The other relevant construct is intention to use. The stream of research on TAM and subsequent researches on IT continuance, have established the fact that IT adoption as well as continued IT use is linked to the intention to use the technology. Although the construct of Intention to Use is not directly linked to our study, for the sake of understanding how Prior Experience and Habit affect CT usage, we need to include this construct into our model. Hence we hypothesize that -

o H1: Habit Strength positively affects Intention to Use

o H2: Habit Strength positively affects Technology Usage

The use of collaborative technology and particularly the social computing technologies from an early age can affect the way people communicate. People's exposure to particular technologies outside of work can significantly affect the way they think about communication and co-ordination even within the work environment. Hence we hypothesize that -

o H3: Habit Strength positively affects Knowledge of CT Capabilities

o H4: Habit Strength positively affects Team Interactions

The intention to use a technology has been linked to the actual usage of the technology in earlier studies (e.g. [42],[1] ) hence we hypothesize that -

H5: Intention to Use a Technology positively influences the Usage of Collaborative Technology

c) Knowledge of Technology Capabilities: The capabilities of a technology are a key determinant of its usage. Media Richness theories [20] posit that there are a number of characteristics of the media, as discussed earlier, which determine its usage for co-ordination purposes. Whereas, Task Technology Fit [23] and Media Synchronity Theories [21] posit that the fit of the task with the media / technology capabilities is a key determinant in its usage for collaboration. Viewing CTs as a bundle of capabilities on the other hand, suggests that some capabilities limit certain aspects of traditional face to face communication while other capabilities enhance them [4]. It has also been theorized that the richness of the channels increases with the users experience with the use of those media channels [27]. This can be linked to the users increase in knowledge of the capabilities of technology. For this paper we would like to use the dimensions of technology as proposed by Becker et al [5]. In the paper, the authors have conceptualized the dimensions of technology as additive and reductive capabilities. Further they have argued that the knowledge of these additive and reductive capabilities impact the dimensions of Collaborative Technology Use. Hence based on observations from these two schools of thought, we hypothesize that -

H6: Knowledge of Collaborative Technology Capabilities positively affects Technology Usage

H7: Knowledge of Collaborative Technology Capabilities positively affects Team Interaction

d) Collaborative Technology Usage: The importance of collaborative technology in virtual teams has already been discussed earlier in the paper. As discussed by Carte and Chidambaram [4], the additive and reductive capabilities of the media lead to better team interaction through the mediating role of technology usage. The knowledge of the capabilities can be effective only when users begin using the communication media. Hence, we hypothesize that -

H8: Collaborative Technology Usage positively affects Team interaction

e) Facilitating Conditions: Organization policies influence both personal and official usage of the social software technologies [43]. Such policies and the groups internal processes can be viewed as being similar to facilitating conditions or social influence from the TAM literature. Facilitating conditions have been shown to impact technology adoption and usage intentions in a number of studies (e.g. [42], [1]). Hence to understand the effect of prior experience and technology usage on team interactions, we also need to include proxies for such team and organization level characteristics. We use Facilitating Conditions as a proxy term which includes a set of such facilitating conditions, social influences, organizational policies and task characteristics. Thus we hypothesize that -

o H9: Facilitating Conditions positively affects Social Software usage for collaboration

o H10: Facilitating Conditions positively affects Team Interactions

\section{Proposed Methodology}

\section{A. Research Design}

In this research we aim to test a number of hypotheses that we have developed. Further we believe that the phenomenon has an objective reality which can be measured and the relationships within the constructs can be captured through data with reasonable representativeness and accuracy. This form of an epistemological stance can be addressed through a quantitative positivist research [46]. We intend to carry out a field study to understand the relationships between the 
TABLE II

OPERATIONALIZATION OF CONSTRUCTS

\begin{tabular}{|c|c|c|c|}
\hline Construct & Sub construct & Definition & Source \\
\hline Habit & None & $\begin{array}{l}\text { Learned sequences of acts that have become automatic } \\
\text { responses to specific cues, and are functional in obtaining } \\
\text { certain goals or end-states }\end{array}$ & [44] \\
\hline $\begin{array}{l}\text { Intention to } \\
\text { Use }\end{array}$ & None & User's intention to use a particular technology & {$[1],[42]$} \\
\hline $\begin{array}{l}\text { Technology } \\
\text { Usage }\end{array}$ & None & User's actual usage of the technology & {$[1],[42]$} \\
\hline \multirow{2}{*}{$\begin{array}{l}\text { Knowledge } \\
\text { of } \\
\text { Technology } \\
\text { Capabili- } \\
\text { ties }\end{array}$} & $\begin{array}{l}\text { Knowledge of } \\
\text { Additive Ca- } \\
\text { pabilities }\end{array}$ & $\begin{array}{l}\text { Knowledge of those features of the collaborative technol- } \\
\text { ogy which add elements to normal communication patterns } \\
\text { (e.g., an electronic record of all communication), }\end{array}$ & {$[5]$} \\
\hline & $\begin{array}{l}\text { Knowledge of } \\
\text { Reductive Ca- } \\
\text { pabilities }\end{array}$ & $\begin{array}{l}\text { Knowledge of those features which remove elements of } \\
\text { normal communication patterns (e.g., visual anonymity) }\end{array}$ & {$[5]$} \\
\hline $\begin{array}{l}\text { Facilitating } \\
\text { Condition }\end{array}$ & None & $\begin{array}{l}\text { The degree to which an individual believes that an organi- } \\
\text { zational and technical infrastructure exists to support use } \\
\text { of the system }\end{array}$ & {$[1],[42]$} \\
\hline \multirow[t]{3}{*}{$\begin{array}{l}\text { Team Inter- } \\
\text { actions }\end{array}$} & Relational conflict & $\begin{array}{l}\text { Interpersonal incompatibilities among group members, } \\
\text { which typically include tension, animosity, and annoyance } \\
\text { among members within a group }\end{array}$ & {$[45]$} \\
\hline & Task Based Conflict & $\begin{array}{l}\text { Disagreements among group members about the content } \\
\text { of the tasks being performed, including differences in } \\
\text { viewpoints, ideas, and opinions }\end{array}$ & [45] \\
\hline & Cohesiveness & $\begin{array}{l}\text { The extent to which members are attracted to the group } \\
\text { and to each other }\end{array}$ & {$[25]$} \\
\hline
\end{tabular}

various constructs mentioned in our model. We are currently in the process of getting the necessary clearance from two top IT companies in India for administering a structured questionnaire. The study is to be administered on people working in a virtual team (i.e., not all members of the team can be collocated ) who use collaborative technology for their work. Considering the number of indicators and relationships in our structural model, we are looking at a sample of about 200-300 individuals spread across 10-15 groups. Further, if possible, a two time period analysis can also be done to compare between the intention to use and the actual usage of the technology.

\section{B. Measures, Measurement Validity and Reliability}

Constructs and measures for measuring the variables have been adopted from previous studies wherever possible. Using prior instruments ensures good measurement validity. All the measures are self-reported measures. Table II lists the important variables and the sources from which they have been adopted. Since we are modifying some of the items to measure the latent variables, we intend to carry out a pre-test and a pilot test to ensure measurement validity.

\section{DATA Analysis Plan}

We intend to carry out Structured Equation Modeling or PLS to test the theoretical model. PLS is a second generation data analysis technique that can be used for statistical conclusion validity [47]. PLS has the ability to model latent constructs under conditions of non-normality as well as small to medium sample sizes [1]. PLS's ability to include multiple measures for each construct also provides more accurate estimates of the paths among constructs, which is typically biased downward by measurement error when using techniques such as multiple regression [1].

\section{Discussions}

\section{A. Contributions to Research}

This research will enhance the understanding of how collaborative tool usage is affected by the team members' diversity in habits with technology outside the organization. It will also provide theoretical justifications on why it is important to look beyond the current models of technology usage for the new class of technologies and a new generation of users. It will also provide a theoretical framework for understanding what are the important constructs and how they are related when understanding the role of habits in social computing tool usage. Hence the research will have important implications for future design research in collaborative tools with social computing capabilities for use in teams and communities.

\section{B. Contributions to Practice}

The use of social networking technology in support of virtual work is an area of growing importance for the organization. Managers are still uncertain, confused and have 
divergent views on the usefulness of the various forms of social media use in organizations. There are more instances now, where people have more advanced technology at home than at work, a paradigm shift from the earlier generations. Hence people get habituated to using such advanced tools and develop knowledge about the capabilities of such tools. It will be a great advantage to the managers if they can learn about ways these competencies in the new employees can be leveraged in their teams. At the same time, the organizations face the difficult problem of not overloading people with unnecessary technologies, when they do not see any advantages from it. There is a need for answers to many such questions relating to the use of the emergent group of technologies by all generations of people.

\section{Limitations and Further Research}

The next step in the research is to test the theoretical model developed in the paper. For parsimony of the model a number of factors have been ignored. These include task variety and time. Future work can extend the analysis and include life cycle of teams and across a number of organizations. Finally collaborative tools can be designed which can leverage the knowledge of the individuals in a more effective manner.

\section{REFERENCES}

[1] S. G. Hirt and M. Lumayem, "Force of habit and information systems usage: Theory and initial validation." Journal of the Association for Information Systems, vol. 4, no. 97, p. 6595, 2003.

[2] C. Liao, P. Palvia, and H. N. Lin, "The roles of habit and web site quality in e-commerce," International Journal of Information Management, vol. 26, no. 6, p. 469483, 2006.

[3] A. Ortiz de Guinea and M. L. Markus, "Why break the habit of a lifetime? rethinking the roles of intention, habit, and emotion in continuing information technology use," Management Information Systems Quarterly, vol. 33, no. 3, p. 433444, 2009.

[4] T. Carte and L. Chidambaram, "A capabilities-based theory of technology deployment in diverse teams: Leapfrogging the pitfalls of diversity and leveraging its potential with collaborative technology," Journal of the Association for Information Systems, vol. 5, no. 11, p. 17, 2004.

[5] A. Becker, T. Carte, and L. Chidambaram, "The effects of collaborative technology appropriation on group outcomes," in DIGIT 2008 Proceed ings, 2008, p. 1.

[6] G. Hertel, S. Geister, and U. Konradt, "Managing virtual teams: A review of current empirical research," Human Resource Management Review, vol. 15 , no. 1 , p. 6995,2005

[7] R. Easley, S. Devaraj, and J. Crant, "Relating collaborative technology use to teamwork quality and performance: An empirical analysis," Journal of Management Information Systems, vol. 19, no. 4, pp. 247268, 2003

[8] M. Parameswaran and A. B. Whinston, "Research issues in social computing," Journal of the Association for Information Systems, vol. 8, no. 6, p. 336-350, 2007.

[9] F. Buytendijk, B. Cripe, R. Henson, and K. Pulverman, "Business management in the age of enterprise 2.0: Why business model 1.0 will obsolete you," Oracle Corporation, December, 2008.

[10] M. Prensky, "Digital natives, digital immigrants part 1," On the horizon, vol. 9, no. 5, p. 1-6, 2001.

[11] C. Cheung and M. Limayem, "The role of habit in information systems continuance: Examining the evolving relationship between intention and usage," ICIS 2005 Proceedings, p. 39, 2005.

[12] M. Maznevski and K. Chudoba, "Bridging space over time: Global virtual team dynamics and effectiveness," Organization science, pp. $473-$ 492, 2000.

[13] J. Lipnack and J. Stamps, Virtual teams: People working across boundaries with technology. John Wiley \& Sons Inc, 2000.
[14] N. Zakaria, A. Amelinckx, and D. Wilemon, "Working together apart? building a knowledge-sharing culture for global virtual teams," Creativity and Innovation Management, vol. 13, no. 1, pp. 15-29, 2004.

[15] L. Martins, L. Gilson, and M. Maynard, "Virtual teams: What do we know and where do we go from here?" Journal of management, vol. 30, no. 6 , p. 805, 2004.

[16] S. K. Horwitz and I. B. Horwitz, "The effects of team diversity on team outcomes: A Meta-Analytic review of team demography," Journal of Management, vol. 33, no. 6, pp. 987 -1015, Dec. 2007.

[17] A. Powell, G. Piccoli, and B. Ives, "Virtual teams: a review of current literature and directions for future research," ACM SIGMIS Database, vol. 35 , no. 1, pp. 6-36, 2004.

[18] A. Townsend, S. DeMarie, and A. Hendrickson, "Virtual teams: Technology and the workplace of the future," The Academy of Management Executive (1993-2005), pp. 17-29, 1998.

[19] S. Bakshi and S. Krishna, "The impact of virtuality on the flexibility of virtual teams in software development projects," AMCIS 2008 Proceedings, 2008.

[20] R. L. Daft and R. H. Lengel, "Organizational information requirements, media richness and structural design," Management science, vol. 32, no. 5 , p. 554571, 1986.

[21] A. R. Dennis and J. S. Valacich, "Rethinking media richness: Towards a theory of media synchronicity," in System Sciences, 1999. HICSS-32. Proceedings of the 32nd Annual Hawaii International Conference on, 1999, p. 10pp.

[22] F. Davis, "A technology acceptance model for empirically testing new end-user information systems: theory and results," Sloan School of Management, Massachusetts Institute of Technology, 1986.

[23] D. L. Goodhue and R. L. Thompson, "Task-Technology fit and individual performance," MIS Quarterly, vol. 19, no. 2, pp. 213-236, Jun. 1995.

[24] A. Malhotra and A. Majchrzak, "Communication Context-Dependent technology use in virtual teams," ICIS 2009 Proceedings, p. 181, 2009.

[25] L. Chidambaram, "Relational development in computer-supported groups," MIS quarterly, pp. 143-165, 1996.

[26] N. Kock, "Media richness or media naturalness? the evolution of our biological communication apparatus and its influence on our behavior toward e-communication tools," Professional Communication, IEEE Transactions on, vol. 48, no. 2, pp. 117-130, 2005.

[27] J. R. Carlson and R. W. Zmud, "Channel expansion theory and the experiential nature of media richness perceptions," The Academy of Management Journal, vol. 42, no. 2, p. 153170, 1999.

[28] P. Raeth, S. Smolnik, N. Urbach, and C. Zimmer, "Towards assessing the success of social software in corporate environments," AMCIS 2009 Proceedings, p. 662, 2009.

[29] C. Hsu and J. Lin, "Acceptance of blog usage: The roles of technology acceptance, social influence and knowledge sharing motivation," Information \& Management, vol. 45, no. 1, pp. 65-74, 2008.

[30] D. Zhao and M. B. Rosson, "How and why people twitter: the role that micro-blogging plays in informal communication at work," in Proceedings of the ACM 2009 international conference on Supporting group work, 2009, p. 243-252.

[31] S. Vodanovich, D. Sundaram, and M. Myers, "Research Commentary-Digital natives and ubiquitous information systems," Information Systems Research, vol. 21, no. 4, p. 711-723, 2010.

[32] J. Palfrey and U. Gasser, Born digital: Understanding the first generation of digital natives. Basic Books, 2010.

[33] D. Tapscott, Grown up digital: How the net generation is changing your world. McGraw-Hill Professional, 2009.

[34] M. Prensky and B. D. Berry, "Do they really think differently?" On the horizon, vol. 9, no. 6, p. 1-7, 2001.

[35] A. McAfee, Enterprise 2.0: New collaborative tools for your organization's toughest challenges. Harvard Business School Press, 2009.

[36] J. D. Becker and M. Cline, "Effectiveness of collaborative tool usage for virtual team activities," AMCIS 2005 Proceedings, p. 3, 2005.

[37] E. Hobman, P. Bordia, B. Irmer, and A. Chang, "The expression of conflict in computer-mediated and face-to-face groups," Small Group Research, vol. 33, no. 4, p. 439, 2002.

[38] T. Liang, C. Liu, T. Lin, and B. Lin, "Effect of team diversity on software project performance," Industrial Management \& Data Systems, vol. 107, no. 5 , pp. 636-653, 2007

[39] M. Montoya-Weiss, A. Massey, and M. Song, "Getting it together: Temporal coordination and conflict management in global virtual teams," Academy of Management Journal, pp. 1251-1262, 2001. 
[40] E. Wilson, E. Mao, and N. Lankton, "The distinct roles of prior it use and habit strength in predicting continued sporadic use of it," Communications of the Association for Information Systems, vol. 27, no. 1, p. 12, 2010.

[41] M. Limayem, S. G. Hirt, and C. M. Cheung, "How habit limits the predictive power of intention: The case of information systems continuance," Management Information Systems Quarterly, vol. 31, no. 4, p. 705737, 2008.

[42] V. Venkatesh, M. Morris, G. Davis, and F. Davis, "User acceptance of information technology: Toward a unified view," MIS quarterly, pp. 425-478, 2003.

[43] R. Ip, "Uses of social software in personal and organizational settings," AMCIS 2007 Proceedings, p. 483, 2007.
[44] B. Verplanken and S. Orbell, "Reflections on past behavior: A self-report index of habit strength," Journal of Applied Social Psychology, vol. 33, no. 6, pp. 1313-1330, 2003.

[45] K. Jehn, "A multimethod examination of the benefits and detriments of intragroup conflict," Administrative science quarterly, pp. 256-282, 1995.

[46] D. Straub, M. Boudreau, and D. Gefen, "Validation guidelines for IS positivist research," Communications of the Association for Information Systems, vol. 13, no. 1, p. 24, 2004.

[47] D. Gefen, D. Straub, and M. Boudreau, "Structural equation modeling and regression: Guidelines for research practice," Communications of the Association for Information Systems, vol. 4, no. 1, p. 7, 2000. 